\title{
Antimicrobial Analysis of Polygonam barbatum Leaf Extracts
}

\section{P. Loganathan ${ }^{\#}$ and P. Malathy}

\author{
Dept. of Bio-Science \\ Vavuniya Campus of the University of Jaffna, Sri Lanka \\ \#Corresponding Author
}

Tele: (94) 24222 0179; Fax: (94) 24222 0179; E-mail: puvanalogan@gmail.com

\begin{abstract}
Polygonum barbatum, known as atalari (in Tamil) or ratu kimbulwenna (in Sinhala), are perennial herbs of the family polygonaceae have been widely used anciently to treat various ailments including infections, fever, pain and tumor. In this study bioassays were carried out to analyse antibacterial activity by using leaves of Polygonum barbatum. Crude extracts were prepared from leaves by sequential extraction method, first by dichloro methane (DCM) then by ethyl acetate (EA) and finally by ethanol (EtOH). These were tested against gram positive bacteria Bacillus subtilis, Staphylococcus aureus and gram negative bacteria Escherichia coli, Pseudomonas aeruginosa by agar well diffusion method. Ethanolic extracts showed a higher inhibition zones for all tested pathogens when compared with other extracts DCM and EA. Antibiotic streptomycin was used as a control for this analysis. The results revealed that the antibacterial activities of ethanolic extract of this plant was comparable to those of selected chemical antibiotic and suggesting its potential as alternative to the commercially available antibiotics in the treatment of infections caused by these microorganisms.
\end{abstract}

KEYWORDS: Antibacterial activity, Phytochemicals, Sequential extraction, Polygonam barbatum

\section{Introduction}

Medicinal plants have many traditional claims including the treatment of ailments of infectious origin. In the evaluation of traditional claims scientific research is important. In the present study an attempt was made to examine the sensitivity of pathogens to dichloro methane, ethyl acetate and ethanol extracts of P. barbatum.

The common names of Polygonam sp include joint weed, knotgrass and smartweed. Stem of $P$. barbatum is cylindrical, hollow, thickened at the nodes and leaves are long and tapering at both ends (Figure 1). Flowers are present in short, slender pedicels and perianth is white or purplish colour. P. barbatum is an annual herb 
distributed throughout the hotter places of Sri Lanka, India, Thailand, Bangladesh and South East Asia. This is mainly found in marshy and aquatic places, by the sides of the river, seasonally flooded roadsides and in small ponds and it has been used traditionally in Siddha system of medicines to treat various diseases. Jeyaweera (2006) reported that the leaf powder of P.barbatum possess wound healing property, decoction of leaves used to wash off ulcers in China, seeds are used to relief colic in Malabar and Canara, roots are used as astringent in Brazil and seeds have aromatic, purgative and emetic action. Jeyaweera (2006) also reported that P.barbatum contains protein (15.7\%), fat (2.1\%), fiber (20.7), carbohydrate $(50.4 \%)$ and minerals $(11.1 \%)$.

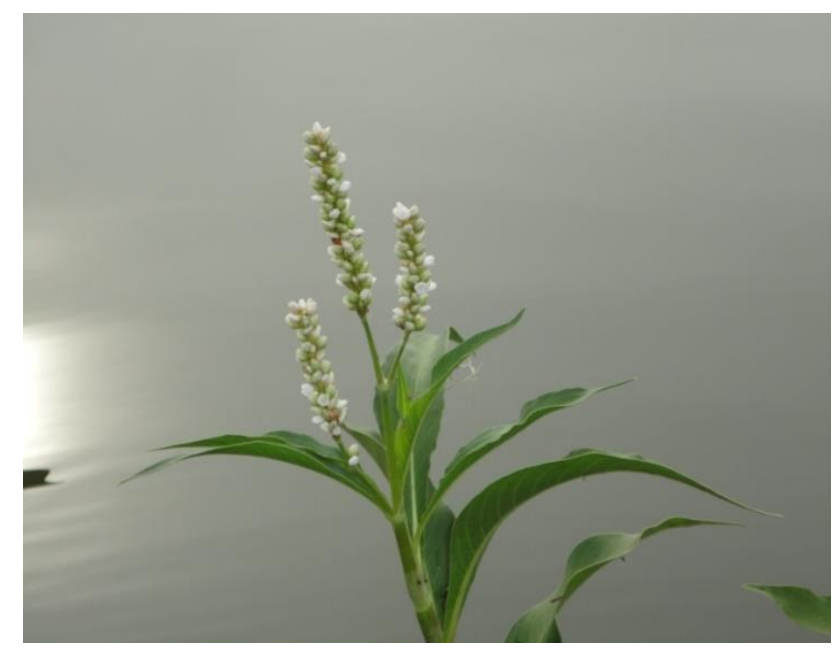

Figure 1: Polygonam barbatum

P.barbatum is abundantly present in Vavuniya tank as aquatic weeds. The effect of antibacterial activity of the leaf extract by direct extraction method, using 95\% EtOH which had already been reported in the past by Queen Rosary Sheela et al. (2011). Therefore the aim of this study was to find the antibacterial activity of leaf extract by sequential extraction method using different solvents of varying polarity. Presents of secondary metabolites are the major components for the antimicrobial activities of plant extracts. Major phytochemical constituents found in P. barbatum are flavanone (Queen Rosary Sheela et al., 2011), sitosterol, viscozulenic acid and acetophenone (Mazid et al., 2011).

The structures of these compounds are as follows.<smiles>COc1c(O)cc2c(c1O)C(=O)CC(c1cc(O)ccc1O)O2</smiles><smiles>C/C=C(/C)C1Oc2c(O)c(OC)cc(O)c2C(=O)C1O</smiles>

Flavanones 


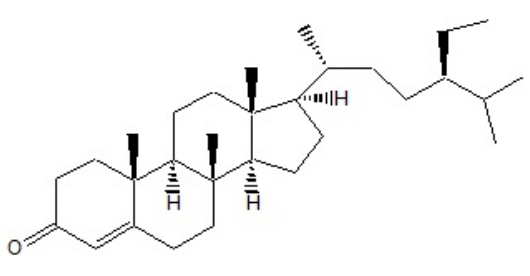

Sitosterone

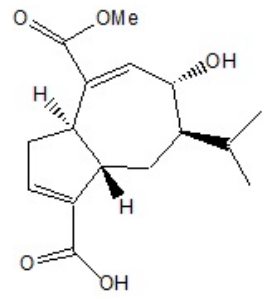

Viscozulenic acid

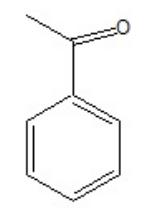

Acetophenone

\section{Materials and Methods}

\section{Preparation of Leaf Powder}

Fresh leaves of P.barbatum were collected from Vavuniya Tank, Vavuniya in May 2012 and they were washed with tap water to remove unwanted particles. Leaves were dried in shade and ground well into fine powder in an electric grinder and stored in air sealed polythene bags at $4^{\circ} \mathrm{C}$ in refrigerator before extraction.

\section{Preparation of Leaf Extracts}

Seventy grams of leaf powder was taken in a stoppered bottle. Two hundred and fifty $\mathrm{mL}$ of DCM was added and soaked for three days. Bottles were intermittently shaken. After three days the supernatant was collected and this procedure was repeated further twice to ensure the complete separation of all the constituents which were dissolved in DCM. Then the extracts were pooled together. Then the remaining powder sample was opened to air dry. A Similar procedure was adopted with ethyl acetate solvent and ethanol solvent. The solvent in the extract was evaporated to dryness under reduced pressure and reduced temperature (i.e. lower than the boiling point of the solvent) by using rotary evaporator.

\section{Antibacterial Assay}

In vitro anti-bacterial activity of extracts was studied against human pathogenic bacteria namely P.aeruginosa, S.aureus, E.coli, B.subtilis obtained from the Department of Microbiology of the Faculty of Medicine of the University of Jaffna. The antibacterial assay was performed by agar well diffusion method according to Patience (2006); $10^{6}$ cells $/ \mathrm{mL}$ bacterial suspensions were prepared by tenfold 
dilution method. Haemocytometer was used to count the bacterial cells. One mL of bacterial suspension was added into sterile petridish.

Then twenty $\mathrm{mL}$ of molten nutrient agar was added on to it and rotated slowly to ensure the uniform distribution of the microorganisms. Then it was allowed to solidify. Four wells were made in the plates with the help of eight mm cork borer. Test extract were dissolved in acetone and mother solvent. $100 \mu \mathrm{L}$ of the test solutions such as $10 \mathrm{mg} / 100 \mu \mathrm{L}, 30 \mathrm{mg} / 100 \mu \mathrm{L}, 50 \mathrm{mg} / 100 \mu \mathrm{L}$, and streptomycin $(1 \mathrm{mg} / 1 \mathrm{~mL})$ were dispensed separately into the well with the help of micropipette. Streptomycin $(1 \mathrm{mg} / 1 \mathrm{~mL})$ was used as standard. These plates were incubated at $37^{\circ} \mathrm{C}$ and inhibition zones were recorded at regular time intervals $(24 \mathrm{~h}, 48 \mathrm{~h}$ and $72 \mathrm{~h})$.

\section{Results and Discussion}

The results pointed out that the EtOH extract showed a higher inhibition zone for all tested pathogens than other two extracts (Figure 2). EtOH extract of P.barbatum showed a higher inhibition zone for all tested pathogens than that of standard antibiotic streptomycin. Antibacterial activity of DCM extract (Table 1) and EA extract (Table 2) showed a maximum inhibition zone of $11.5 \mathrm{~mm}$ for P.aeruginosa and $15 \mathrm{~mm}$ for Bacillus w respectively. $50 \mathrm{mg} / 100 \mu \mathrm{L}$ of this extract inhibit the growth of S.aureus, Bacillus, E.coli and P.aeruginosa with the zone of inhibition of $26 \mathrm{~mm}, 24 \mathrm{~mm}, 25 \mathrm{~mm}$ and $21 \mathrm{~mm}$ respectively after 72 hours of incubation period (Table 3).

Streptomycin could not affect the growth of E.coli but the ethanol extract (Plate No. 01) of this plant inhibit the growth of this bacterial pathogen with a large inhibition zone of $21 \mathrm{~mm}$ after 48 hours of incubation. DCM and ethylacetate extracts of this plant showed minimum inhibition zones for these four bacterial pathogens. Time course analysis indicated that there was no considerable change in the inhibitory effect after 48 hours (Figure 3).

Ethanol extract of $P$. barbatum was the good extract which was obtained by a sequential extraction method of leaf extract first by DCM (Plate No. 5 and 6) and then by EA (Plate No. 7 and 8) finally by EtOH (Plate No. 1, 2, 3 and 4). The result of this study forms a good basis for selection of this plant for further phytochemical and pharmacological investigation for their use as possible antimicrobial agent for the treatment of various infections.

Plates illustrating the effect of different extracts of $P$. barbatum on the growth of tested pathogens are as follows. Here 10, 30, 50 and std indicates $10 \mathrm{mg} / 100 \mu \mathrm{L}, 30$ $\mathrm{mg} / 100 \mu \mathrm{L}, 50 \mathrm{mg} / 100 \mu \mathrm{L}$ of the crude extract and standard antibiotic respectively. In each plates dark circled area around well indicates the extent of inhibition of growth of a particular microorganism by a specific concentration of crude extract. Other than this area (whitish color) indicates the intense growth of bacteria. 
Plate 1: Effect of EtOH extract on the growth of E. coli

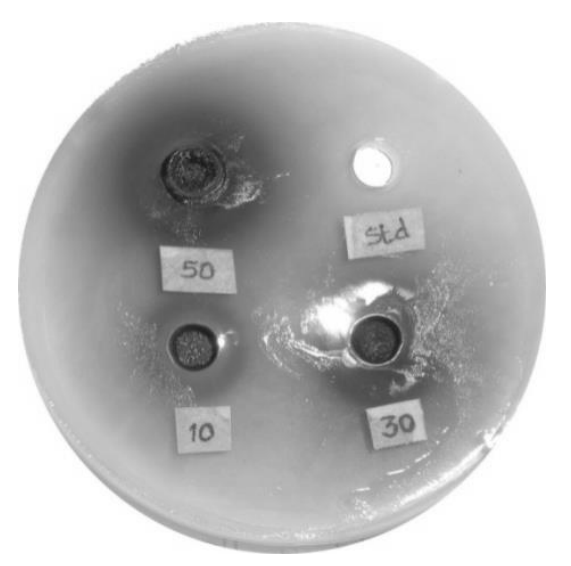

Plate 2: Effect of EtOH extract on the growth of S. aureus

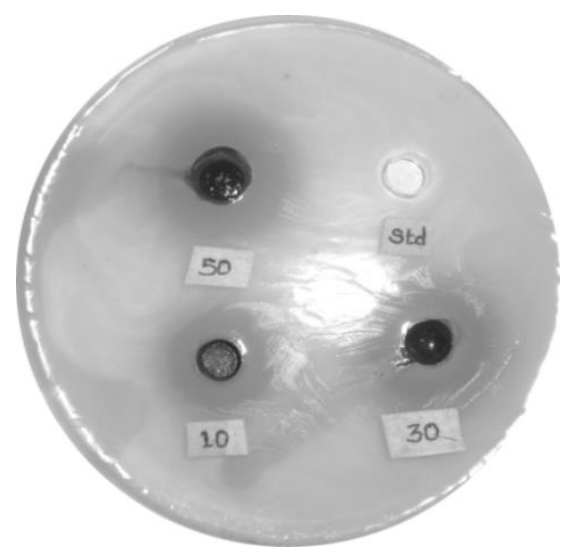

Plate 3: Effect of EtOH extract on the growth of Bacillus

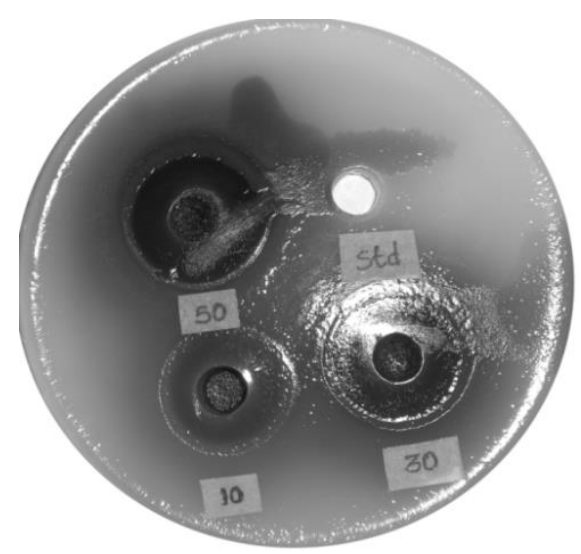


Plate 4: Effect of EtOH extract on the growth of P. aeruginosa

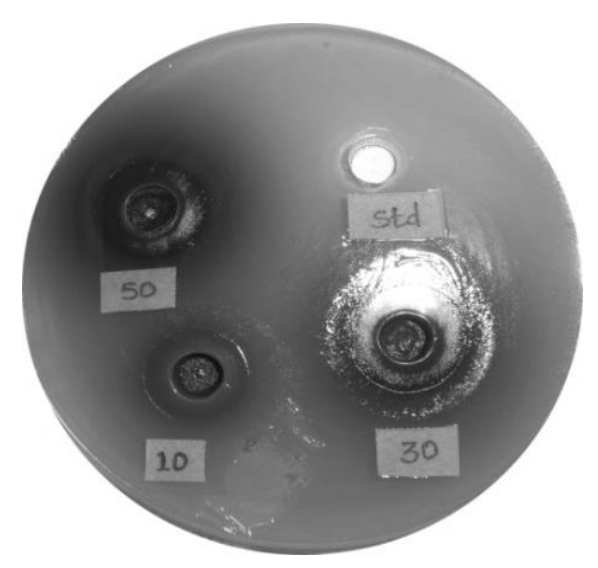

Plate 5: Effect of DCM extract on the growth of Bacillus

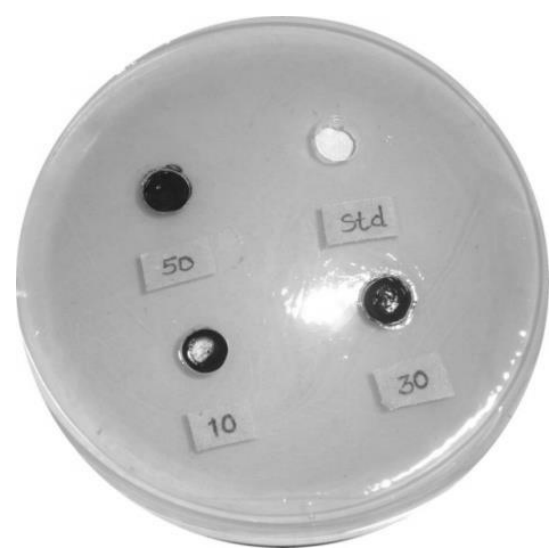

Plate 6: Effect of DCM extract on the growth of $S$. aureus

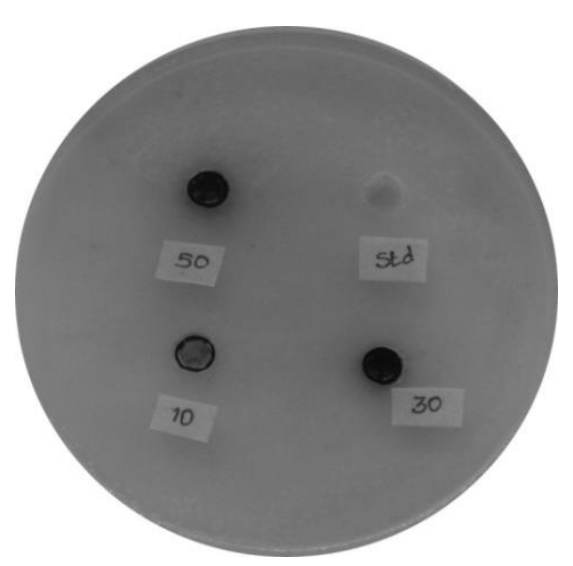


Plate 7: Effect of EA extract on the growth of Bacillus

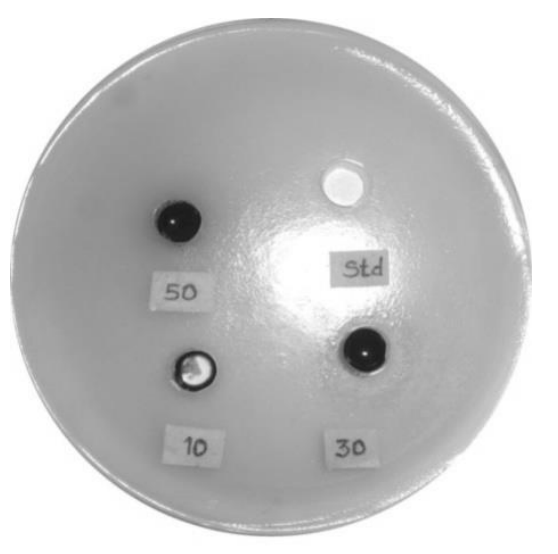

Plate 8: Effect of EA extract on the growth of $S$. aureus

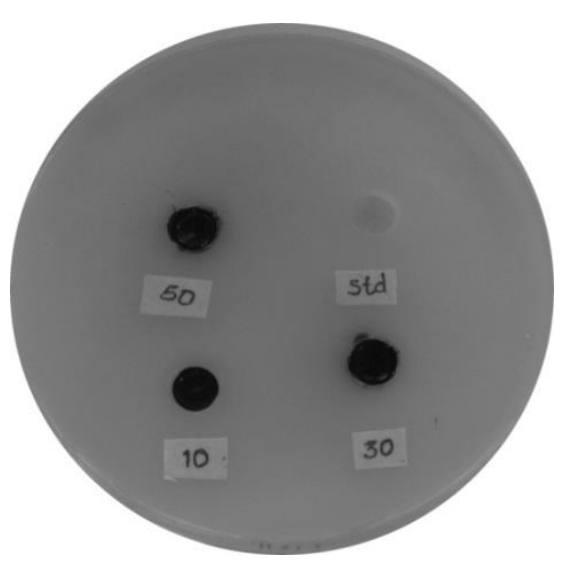


Table 1: Antibacterial activity of $P$. barbatum (DCM extract)

\begin{tabular}{|c|c|c|c|c|c|c|c|c|c|c|c|c|}
\hline \multirow{3}{*}{ 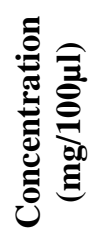 } & \multicolumn{12}{|c|}{ Diameter of inhibition zone in $\mathbf{m m}$} \\
\hline & \multicolumn{3}{|c|}{ S. aureus } & \multicolumn{3}{|c|}{ Bacillus w } & \multicolumn{3}{|c|}{ P. aeruginosa } & \multicolumn{3}{|c|}{ E. coli } \\
\hline & $24 \mathrm{~h}$ & $48 \mathrm{~h}$ & $72 \mathrm{~h}$ & $24 h$ & $48 h$ & $72 \mathrm{~h}$ & $24 h$ & $48 h$ & $72 \mathrm{~h}$ & $24 \mathrm{~h}$ & $48 \mathrm{~h}$ & $72 \mathrm{~h}$ \\
\hline 10 & - & - & - & 9.0 & 9.5 & 9.5 & 10.0 & 10.5 & 10.0 & - & - & - \\
\hline 30 & 9.5 & 10.0 & 9.5 & 9.0 & 9.0 & 9.0 & 10.5 & 10.5 & 10.0 & - & - & - \\
\hline 50 & 10.0 & 10.0 & 10.0 & 10.0 & 10.5 & 10.0 & 11.5 & 11.0 & 11.0 & 9.0 & 9.5 & 9.0 \\
\hline Std & 11.0 & 11.5 & 12 & 10.0 & 13 & 13 & 12.0 & 12 & 12 & - & - & - \\
\hline
\end{tabular}

Table 2: Antibacterial activity of $P$. barbatum (EA extract)

\begin{tabular}{|c|c|c|c|c|c|c|c|c|c|c|c|c|}
\hline \multirow{3}{*}{ 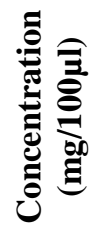 } & \multicolumn{12}{|c|}{ Diameter of inhibition zone in $\mathrm{mm}$} \\
\hline & \multicolumn{3}{|c|}{ S. aureus } & \multicolumn{3}{|c|}{ Bacillus w } & \multicolumn{3}{|c|}{ P. aeruginosa } & \multicolumn{3}{|c|}{ E. coli } \\
\hline & $24 h$ & $48 h$ & $72 \mathrm{~h}$ & $24 \mathrm{~h}$ & $48 h$ & 72h & $24 \mathrm{~h}$ & $48 \mathrm{~h}$ & 72h & $24 \mathrm{~h}$ & $48 h$ & $72 \mathrm{~h}$ \\
\hline 10 & - & - & - & 9.0 & 9.5 & 9.0 & 9.0 & 9.5 & 9.0 & 9.0 & 9.5 & 9.5 \\
\hline 30 & 9.5 & 9.5 & 9.0 & 10.0 & 10.0 & 10.0 & 9.0 & 9.5 & 9.5 & 9.0 & 9.0 & 9.0 \\
\hline 50 & 9.5 & 10.0 & 10.0 & 15.0 & 14.0 & 14.0 & 9.0 & 9.0 & 9.0 & 9.0 & 10.0 & 10.0 \\
\hline Std & 15 & 15 & 15.5 & 14 & 14.5 & 14.5 & 13 & 13.5 & 13 & - & - & - \\
\hline
\end{tabular}

Table 3: Antibacterial activity of $P$. barbatum (EtOH extract)

\begin{tabular}{|c|c|c|c|c|c|c|c|c|c|c|c|c|}
\hline \multirow{3}{*}{ 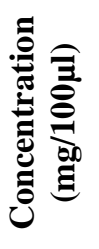 } & \multicolumn{12}{|c|}{ Diameter of inhibition zone in $\mathbf{~ m m}$} \\
\hline & \multicolumn{3}{|c|}{ S. aureus } & \multicolumn{3}{|c|}{ Bacillus w } & \multicolumn{3}{|c|}{ P. aeruginosa } & \multicolumn{3}{|c|}{ E. coli } \\
\hline & $24 \mathrm{~h}$ & $48 h$ & $72 \mathrm{~h}$ & $24 \mathrm{~h}$ & $48 h$ & $72 \mathrm{~h}$ & $24 \mathrm{~h}$ & $48 h$ & $72 h$ & $24 \mathrm{~h}$ & $48 h$ & $72 \mathrm{~h}$ \\
\hline 10 & 16.0 & 18.0 & 18.0 & 14.0 & 20.0 & 20.0 & 17.0 & 17.0 & 17.0 & 16.0 & 16.5 & 16.5 \\
\hline 30 & 18.0 & 23.0 & 23.0 & 20.0 & 21.0 & 21.0 & 20.0 & 24.0 & 24.0 & 18.0 & 18.5 & 18.5 \\
\hline 50 & 18.5 & 25.0 & 26.0 & 22.0 & 24.0 & 24.0 & 23.0 & 24.0 & 25.0 & 19.0 & 21.0 & 21.0 \\
\hline Std & 10 & 10.5 & 11 & 13 & 13.5 & 13.5 & 12.0 & 13 & 14 & - & - & - \\
\hline
\end{tabular}

Note: Indicates that there was no antibacterial activity. Inhibition zones include the diameter of well $(8 \mathrm{~mm})$ 


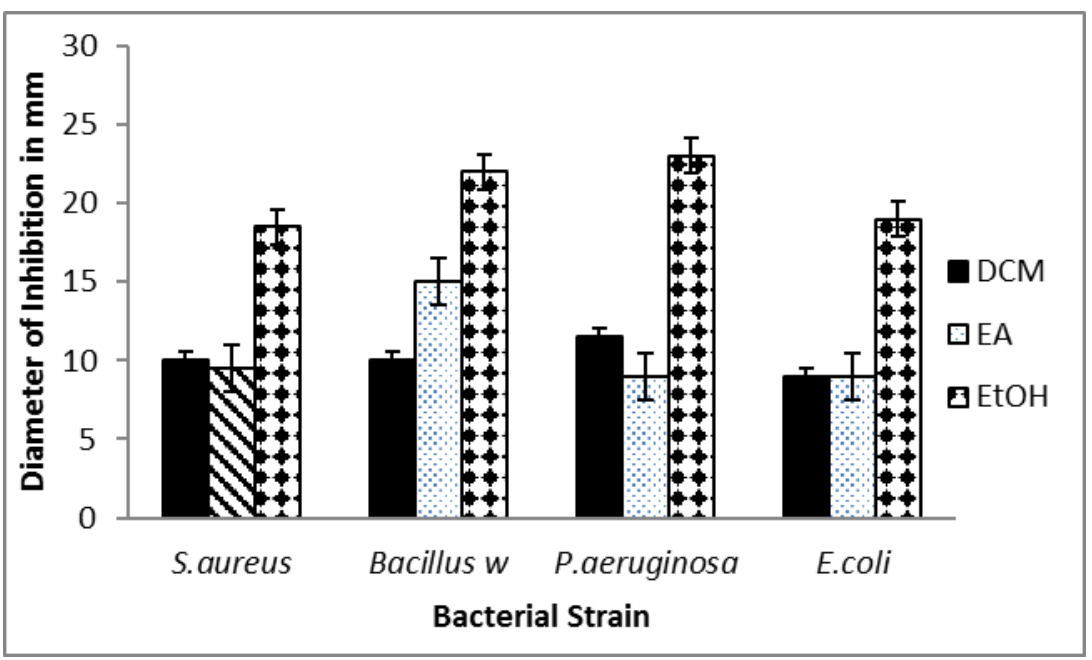

Figure 2: Effect of EtOH, EA and DCM extracts $(50 \mathrm{mg} / 100 \mu \mathrm{L})$ on tested pathogens after $24 \mathrm{hrs}$ of incubation

Here the EtOH extract showed higher inhibition zone than the other ones.

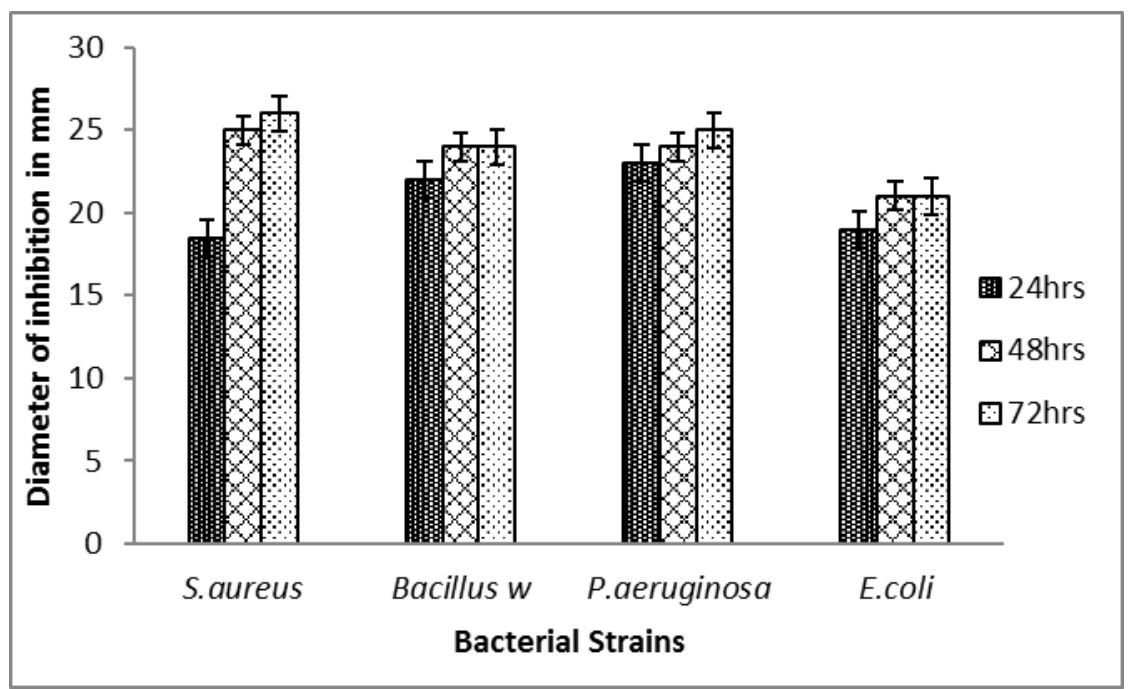

Figure 3: Effect of EtOH extract $(50 \mathrm{mg} / 100 \mu \mathrm{L})$ on tested pathogens at different incubation period

Incubation zones increases with increasing incubation periods. But commonly higher inhibition zone can be observed at 48 hours of incubation.

Queen Rosary Sheela and Ramani (2011) analysed the antimicrobial activity of $P$. barbatum leaf extract by hot extraction method by using $95 \% \mathrm{EtOH}$. They used paper disk diffusion method to analyse antimicrobial activity and this is a direct extraction method, they used only one solvent to separate the phytochemical compounds. They also indicate the EtOH extract showed a higher inhibition zones 
for Gram positive and Gram negative bacteria. Therefore there is a need to analyse hot/ direct extraction or cold/ sequential extraction method is a better extraction method by maintaining the experimental conditions as the same for both.

Mazid et al. (2011) reported that the antitumor activity of methanol (MeOH) extract of sun dried, ground aerial parts of $P$. barbatum. Here they first obtained the crude extract by using $\mathrm{MeOH}$ then the obtained $90 \%$ aqueous $\mathrm{MeOH}$ extract and subjected to solvent partitioning with petroleum ether (PE). The resulting aq. $\mathrm{MeOH}$ extract was further partitioned with chloroform and finally by EA. In their study PE extract of $P$. barbatum showed a higher inhibition zone than the other solvents.

\section{Conclusion}

In conclusion the crude extract of ethanol has higher antibacterial activity and this confirmed the historical use of P.barbatum as an antibacterial agent. Here the antibacterial activity was analysed to the crude $\mathrm{EtOH}$ extract. In the crude extract there is a possibility for the presence of other compounds, some will increase/ decrease/ having no activity against bacteria. Therefore there is a need to separate the compounds in this extract and the individual compounds may have greater antibacterial activity than the crude extract. Therefore EtOH extract could be used as initial material for further bioassay guided isolation and purification to find the compound responsible for antibacterial activity.

\section{References}

Ahamad, B., M. Y. Syad and K. Hussain (2003). "Biological activities of P. barbatum" Journal of Research (Science), 14 (2): 169-175, ISSN 1021 -1012.

Jeyaweera, D. M. A. (2006). "With taxonomic updating by Lilinik Senaratna". Medicinal Plants (Indigenous and Exotic) used in Ceylon (Ed.), part iv.

Mazid, M. A., B. K. Datta, L. Nahar, S. A. M. Bashar, S. C. Bachar and S. D. Sarker (2011). "Phytochemical studies of P. barbatum" Record of Natural Product, 5 (2): 143-146.

Patience, O. A. (2006). "Antibacterial activity of aqueous and ethanol extracts of the stem barks of Alstonia boonei and Morinda lucida" Scientific Research and Essay, 1(2): 050-053.

Queen Rosary Sheela and V. A. Ramani (2011). “Antimicrobial Screening of P. barbatum leaf extract” International Journal of Current Pharmaceutical Research, 3.

Queen Rosary Sheela, X., P. Arokiasamy and R. Kanmani (2011). "Isolation and Characterization of Flavanone Compounds from the Leaf extract of P. barbatum" Journal of Chemical and Pharmaceutical Research, 3(2): 762-764. 